\title{
Erratum to: The Effects of Heat Adaptation on Physiology, Perception and Exercise Performance in the Heat: A Meta-Analysis
}

\author{
Christopher J. Tyler ${ }^{1} \cdot$ Tom Reeve $^{1} \cdot$ Gary J. Hodges $^{2} \cdot$ Stephen S. Cheung $^{2}$
}

Published online: 21 June 2016

(c) Springer International Publishing Switzerland 2016

\section{Erratum to: Sports Med \\ DOI 10.1007/s40279-016-0538-5}

Page 3, column 2, section 1.3, paragraph 4, lines 93-7: The following sentence, which previously read:

"Previously, it was suggested that successful HA requires a minimum daily heat exposure of $2 \mathrm{~h} \mathrm{[10],} \mathrm{and} \mathrm{although}$ more recently it has been suggested that a minimum of $1 \mathrm{~h}$ a day is required [8], it is difficult to find data to support either claim".

Should read:

"Previously, it was suggested that successful HA requires a minimum daily heat exposure of $2 \mathrm{~h} \mathrm{[10],} \mathrm{and}$ although more recently it has been suggested that a minimum of $1 \mathrm{~h}$ a day is required [6], it is difficult to find data to support either claim".
Page 21, column 2, section 5, paragraph 1, lines 76-82: The following sentence, which previously read:

"While it has previously been suggested that 7 days of HA is sufficient to induce "optimal" adaptation [8], data from Patterson et al. [31] show that if the thermal impulse is maintained, further benefit can be gained from longer protocols, suggesting that if time allows and an isothermal HA model can be adopted, longer protocols may be preferable".

Should read:

"While it has previously been suggested that 14 days of HA is sufficient to "optimize aerobic performance" [6], data from Patterson et al. [31] show that if the thermal impulse is maintained, further benefit can be gained from longer protocols, suggesting that if time allows and an isothermal HA model can be adopted, longer protocols may be preferable".
The online version of the original article can be found under doi: 10.1007/s40279-016-0538-5.

Christopher J. Tyler

chris.tyler@roehampton.ac.uk

1 Department of Life Sciences, University of Roehampton, Danebury Avenue, London SW15 4JD, England, UK

2 Department of Kinesiology, Brock University, St. Catharines, ON, Canada 